\title{
Lo ideológico del pensamiento neoclásico: La competencia perfecta como mito fundacional
}

\author{
Ideology AND Neoclassical thought: Perfect competence as original Myth
}

Manuel Antonio Jiménez-Castillo (antoniojcastillo@colef.mx) Departamento de Estudios Económicos, El Colegio de la Frontera Norte (Nuevo Laredo, México)

\begin{abstract}
The purpose of this paper aims to unravel the ideological strategy that rises from the well-celebrated epistemic rigor of neoclassical economic thought. From the Economics Nobel Price Paul Krugman's popularized connotation naming to "freshwater" economists as those fervent followers of the most orthodox academic creed, we will expose the logical inconsistency and empirical implausibility of such thought's underlying assumptions: perfect competence and equilibrium's approaching. From a critical analysis that will be conducted from each of those mentioned assumptions, we will argued that the neoclassical thought is an ideological strategy subverting reality's principles, overcoming "artificially" those relevant deficiencies and limitations of its theoretical approach.
\end{abstract}

Keywords: competence, knowledge, equilibrium, ideology, neoclassical school.

\section{Resumen}

A lo largo de este trabajo se intenta desvelar la estrategia ideológica que emana del celebrado rigorismo epistémico del pensamiento neoclásico de economía. Desde la connotación popularizada por el Nobel Paul Krugman a los economistas de "agua dulce" como aquellos fervientes seguidores del credo académico más ortodoxo, expondremos la incoherencia lógica e imposibilidad empírica de los supuestos fundamentales de su pensamiento: competencia perfecta y aproximación al equilibrio. Desde un examen crítico que irá conduciéndose por cada uno de tales supuestos, resolveremos cómo el marco neoclásico no es más que una estrategia ideológica que subvirtiendo los principios de lo real consigue superar solo "artificialmente" las importantes deficiencias y limitaciones de su marco teórico.

Palabras clave: competencia, conocimiento, equilibrio, escuela neoclásica, ideología.

\section{Introducción}

Uno de los aspectos que flotan incombustiblemente sobre la atmósfera más academicista y que resurge en cada crisis económica es aquel al que hace explícita referencia el profesor Mirowski cuando consternado ante el fracaso evidente de los economistas neoclásicos a la hora de predecir y gestionar los resultados de la crisis financiera sostiene que "(...) ninguno de esos profesionales fue despedido por incompetente. Los economistas no han sido expulsados de sus puestos en el Gobierno. Ningún 
departamento de Economía ha sido clausurado, ni por sus errores ni como medida de ahorro de costes" (2013:159).

En este trabajo asumimos desde una dimensión analítica el compromiso de identificar algunas de las razones que hace certero el juicio del profesor de la Universidad de Notre Dame. Frente a lo presentado tradicionalmente por los estudios más heterodoxos en el que se confía tales motivos a una especie de establishment político-financiero donde la rigurosidad y honestidad quedan relegadas por la codicia o la ignorancia: "Lo que ocurrió durante la crisis dejó claro que lo que determinaba la retribución relativa no era la contribución de cada cual a la sociedad, sino otra cosa; los banqueros recibieron enormes recompensas, aunque su aportación a la sociedad e incluso a sus empresas hubiera sido negativa. La riqueza que recibían las élites y los banqueros parecía surgir de su capacidad y voluntad de aprovecharse de los demás" (Stiglitz 2012:8).

Ilustraremos cómo más allá de ello existen razones más profundas que instruyen tal paradójico escenario. Razones que en ningún momento serán presentadas de manera categórica y conclusiva, y sí comedidas por el ánimo de generar un fructífero debate que nos permita ir reconfigurando algunas de las cuestiones epistémicas que condicionan el estudio de lo económico.

Tomaremos como hipótesis aquella por la cual el pensamiento neoclásico genera un marco de lo real desde una serie de premisas ideológicas que no derivan de su corroboración empírica y sí desde un mecanismo ideológico que hace posible interpretar las incoherencias de su modelo presentándolo como distorsión de la realidad misma. Sucesivamente comprobaremos cómo el mecanismo de acción ideológico presente en el pensamiento de los economistas de "agua dulce" -como así identificaremos a los economistas neoclásicos- se revela de su innegable imposibilidad empírica. Para ello nos apoyaremos en algunos de los desarrollos teóricos de la escuela austriaca de economía con un F. Hayek como máximo exponente (aunque bien somos conscientes de las diferencias epistémicas y metodológicas que distinguen a la escuela de pensamiento austriaca de la neoclásica).

Demostraremos cómo en el presente mecanismo de acción ideológica la responsabilidad moral queda desplazada e inserta al propio devenir empírico que, haciendo uso de aquellas expresiones de la realidad no falsables, actúan ellas mismas como velo con el que ocultar las incoherencias del pensamiento neoclásico. Corroborar tal hipótesis exige un ejercicio que cubra la distinción necesaria entre el concepto trascendental de la competencia perfecta, entendido como el orden exigible para alcanzar el estado óptimo de equilibrio general, y por otro, su expresión metodológica como tendencia hacia tal equilibrio. Tras ello, acudiremos a examinar su realismo empírico.

\section{Los economistas de "agua dulce"}

Fue el profesor y premio Nobel de economía Paul Krugman quién recurriendo a uno más de sus innovadores ejercicios periodísticos llegó a ofrecer una genuina clasificación para agrupar a los dos grupos de economistas dominantes en el escenario académico. Distinguiendo entre economistas de "agua salada" y de "agua dulce" pretendía resaltar la diferencia entre aquellos profesionales de posición ideológica más keynesiana-intervencionista frente a los más orientados hacia posiciones liberales-neoclásicas: "macroeconomics has divided into two great factions: saltwater economists, who have a more or less Keynesian vision of what recessions are all about; and freshwater economists, who consider that vision nonsense" (Krugman 2009:13). 
Aunque tal denominación no ha calado en el imaginario profesional con la intensidad que su autor hubiera deseado, su diferenciación responde a dos corrientes ideológicas que han protagonizado el enfrentamiento probablemente más fecundo de esta disciplina "científica". Unos de los clichés que más acostumbran los economistas de cualquier orientación ideológica es aquel donde se llega a sostener que estos "son los únicos capaces de explicar por qué no ocurrió aquello que había sido predicho que así ocurriría". Un juego que más allá de su relación terminológica esconde un significado muy relevante que permite identificar la naturaleza de los instrumentos comúnmente utilizados para la investigación de lo económico. Un significado que atenta peligrosamente contra la realidad compulsiva de unos hechos derivados de la crisis financiera actual, y que generan ineluctablemente un estrechamiento en el campo del entendimiento y la razón.

A pesar de las palpables consecuencias en términos de desocupación de factores productivos, incremento de la desigualdad económica y social, reducción de la renta disponible, caída estrepitosa de la producción nacional, etcétera, las razones que explican tales sucesos siguen siendo tras casi 250 años de la publicación de la Riqueza de las Naciones tan lúgubres como aquellas que explicaron la crisis financiera actual: "the failure to foresee the timing, extent and severity of the crisis and to head it off (...) was principally a failure of the collective imagination of many bright people (...) to understand the crisis as a whole" (Kurz 2010:18). Los motivos de tal acontecimiento serán indirectamente tratados desde el propósito originario de este trabajo.

Las consecuencias derivadas de la actual crisis económica y financiera responde de acuerdo con los economistas de "agua dulce" a un exceso, en términos generales, de intervención política en el sistema económico. Avalados por el principio hayekiano de imposibilidad gnoseológica perfecta donde "el conocimiento (...) nunca se da de una forma concentrada o integrada, sino como fragmentos dispersos de un conocimiento incompleto y contradictorio" (Hayek 1997:219), las deficiencias generadas por el sistema económico derivarían de una siempre impulsiva e irracional intervención sobre las espontáneas adaptaciones generadas en el "mercado libre". Tales intervenciones forjarían "perversos incentivos" que en su proceso de acción invitarían a la aparición de negativos desajustes afectando al proceso de tendencia hacia la ordenación y el equilibrio.

Frente a juicios como el del profesor Skidelsky (o los más recientes trabajos de Piketty) en los que se responsabiliza como causas de la crisis actual a un conjunto de "políticas de corte neo-liberales que habrían supuesto un incremento sin parangón en los niveles de desempleo, desigualdad y precarización social" (Wolf 2015:50), los economistas de "agua dulce" interpretarían tales consecuencias como efecto directo de la instintiva pretensión de control y dirección del policymaker (Wolf 2015). Un policymaker que incapacitado para "conocerlo todo" ha de suponérsele la capacidad para no "conocer nada": "in the absence of market prices for the factors of production, a computation of profit or loss is not feasible" (Von Mises 2010:705). Solo desde esta perversión ideológica radical, los economistas de "agua dulce" pueden enfrentar las dramáticas consecuencias del sistema económico como conjunto de desajustadas maniobras políticas, y liberarse así de la responsabilidad normativa que demanda su implicación en la vida académica y social.

Si a partir del presupuesto de imposibilidad de "conocimiento" perfecto deducimos necesariamente el desconocimiento total de los agentes (Von Mises 2010), el juicio normativo queda desplazado y superado por un rasgo ideológico-trascendental. De este modo se entendería que su implicación por medio de un juicio no-implicativo negara cualquier efecto resultante de su intromisión ideológica y del subjetivismo reinante en la disciplina económica (Zanotti 2011). 


\section{3. "Empiricidad" y competencia perfecta}

Yendo al fondo del asunto en ciernes emerge una cuestión fundamental expresable en los siguientes términos: ¿qué razones explicarían que los economistas de "agua dulce" no se hagan responsables en los términos expresamente detallados por el profesor Mirowski en la introducción?

Un modo de enfocar esta respuesta sería apelar, tal y como sostiene Hinkelammert, al hecho según el cual en las ciencias empíricas la plausibilidad de cualquier acontecimiento no deriva en principio de ninguna correspondencia con su estricto marco categorial y sí de los propios límites de acción que rigen el marco de posibilidad de lo empírico. Este grado extremo de subjetividad es precisamente aquello que imposibilita la concepción trascendental que rige al pensamiento neoclásico y que acaba convirtiéndolo en un sistema ideológico.

Ahora bien, que el pensamiento neoclásico se muestre en términos ideológicos no implica por sí mismo una negación arbitraria de lo empírico. Precisamente, el éxito del pensamiento neoclásico proviene de tomar como eje un rasgo empírico central de la realidad-el individuo como ser auto-interesado-para a partir de él, realizar una proyección al infinito -tendencia al equilibrio general- mediatizada por un progreso infinito de acción-incesantes mejoradas derivadas de la competencia. De este modo, la negación de lo real no ocurre como podría esperarse por medio de una superposición de premisas, sino que aceptando aspectos particulares de la realidad, se diluye desde la formalización ideológica de unos supuestos no falsables.

En palabras de Hinkelammert: "Carácter falsable tienen exclusivamente las condiciones iniciales a través de las cuales esta ley (ley antropológica del individuo auto-interesado) puede aparecer en la realidad, pero ella sola no informa nada sobre la realidad. Si llamamos a todas aquellas leyes que se derivan de manera analítica de algún principio de imposibilidad (el individuo no se consume como ser auto-interesado), leyes generales, se sigue entonces que las leyes generales de las ciencias empíricas no son falsables en principio. Por tanto: si un enunciado científico es falsable, no puede ser una ley empírica general; y si es una ley empírica general no puede ser falsable" (2002:218).

La realidad pierde así su propiedad referencial para constituirse como elemento imprescindible de la formulación ideológica. En este sentido, la realidad ya no es como sostendría Albert en El Mito de la Razón Total "coincidencia necesaria e interna con la teoría" (1961:88), sino que en un ejercicio ideológico radical presenta a lo fáctico como una propia distorsión de sí, para de este modo enfrentar la imposibilidad empírica del pensamiento neoclásico como algo vinculado con la realidad misma.

Examinemos este asunto más detalladamente a partir de los conceptos de competencia perfecta y equilibrio general. La competencia perfecta es en el pensamiento neoclásico la variable focal que fundamenta todo un marco ideológico transportándolo a un equilibrio donde "todos los consumidores pueden gastar sus ingresos según sus preferencias, las empresas venden todos sus productos y servicios producidos cubriendo al menos sus costos, y todos los factores ofrecidos en el mercado son usados en la producción de estos productos" (Hayek 1952:136). ¿Empero, como sostener que tal equilibrio es empíricamente plausible a partir de los exclusivos supuestos que rigen el concepto de competencia perfecta? Y profundizando en el razonamiento, ¿qué sería aquello que permite al pensamiento neoclásico mantenerse indemne frente a la refutación constante de la realidad? Con objeto de responder a estas cuestiones examinaremos primeramente como la competencia perfecta es un concepto trascendental cuya función social de legitimación para el pensamiento neoclásico implica una no realización empírica. 
La primera imposibilidad con la que se topa es de naturaleza lógica pues "en competencia perfecta nadie compite" como sostiene Hinkelammert (2002:67). Llevada al extremo donde el precio se iguala al coste marginal el concepto de competencia supone una imposibilidad absoluta. La competencia exige ausencia de simetrías, y por tanto, desorden. Solo en tal desorden tiene sentido competir. No existe competencia en la perfección. Bajo un estado de perfecta sincronía la rivalidad se torna consenso. En este sentido, hace bien Hinkelammert afirmando que la competencia empírica puede ser cualquier cosa excepto una tendencia hacia la competencia perfecta. No puede haber tendencia hacia ningún equilibrio perfecto que exija como condición necesaria un estado de competencia continua y creciente: "La competencia empírica como proceso real puede muchas cosas, excepto una aproximación lineal a la competencia perfecta; es decir, lo que no puede es precisamente producir una tendencia al equilibrio. [...] No puede haber una tendencia porque el equilibrio es lo contrario de competencia. Competencia es desequilibrio" (2002:141).

Además, la competencia en tales términos solo puede desentrañarse desde un plano general de "ordenación" de la actividad económica. El sistema de competencia puede tratarse entre agentes pero no para agentes. El resultado de la producción y consumo en las sociedades avanzadas no responde en sustancia a lo que de exclusivo tienen los violentos cambios en las señales del mercado. Como sostiene Mandel: "the bulk of current production corresponds to established consumption patterns and predetermined production techniques that are largely if not completely independent of the market" (1986:11). Si bien, el asunto gana en relevancia cuando los economistas de "agua dulce" muestran total indiferencia ante tales hechos. El pensamiento neoclásico nunca advierte de aquello que permita distinguir a favor de los límites empíricos de posibilidad de la competencia perfecta.

Frente a la facticidad de los estados históricos-empíricos, la competencia perfecta se revelaría como un estado meta-histórico donde su función como concepto límite supone "una negación del proceso social de la competencia [...], y por tanto, una contradicción dialéctica de la competencia misma" Hinkelammert (2002:61). Su no factibilidad no deriva de un no ser sino de un no poder ser. Tratar el concepto límite como un estado histórico no acaecido pero no por ello implausible tiene una relevancia radical para la estrategia ideológica. Y es que ahora la imposibilidad de la competencia perfecta no deviene de una no realización empírica, sino de un hecho aún no consumado. A partir de esta relación, el pensamiento neoclásico puede trasladar a un futuro no decible su completa realización de manera que pueda apelar a la intromisión de lo empírico en forma de intervencionismo arbitrario (de lo público) como razón suficiente de su no facticidad.

\section{4. ¿Camino hacia un orden espontáneo?}

Atendiendo al irrealismo empírico que subyace al principio de la competencia perfecta, nos acercaremos en este apartado al segundo de los supuestos vinculado con la hipotética e incorregible tendencia hacia tal estado de equilibrio. Un examen que se presta necesario pues pudiera argüirse que no siendo posible la realización de tal concepto límite, sí se pudiera asegurar su aproximación. Aunque el mismo F. Hayek aduce que "sería absurdo suponer que podemos poseer todos los datos" que permitieran calcular todas las ecuaciones del modelo de competencia perfecta, no ve inconveniente en la facticidad de su aproximación a través del supuesto neoclásico del mercado empírico: libertad de contrato y propiedad privada. No obstante, bajo ninguna circunstancia Hayek establecerá para ninguno de sus trabajos el modo por el cual, desde el mercado "empírico" se alcanzará necesariamente un estado de perfecta competencia.

No existe en este sentido ninguna relación científica entre los fundamentos y su realización que nos exija deducir inexcusablemente tal comportamiento. Incluyendo la hipótesis del aprendizaje, la lógica pura de 
la elección individual se convierte ideológicamente en un supuesto definitivo para la realización de la competencia perfecta. Una hipótesis que no podemos extrapolar a partir de la experiencia, entendiéndola como inferencia necesaria de la "acción humana" en toda su expresión. Esta situación obliga a Hayek a presentar un concepto de lo empírico menos restrictivo que no exija como condición de necesidad aquello "inferido desde los postulados necesarios de la acción humana" (Zanotti 2011:45).

Ahora bien, regresando a la hipótesis presentada y atendiendo desde la corriente más evolucionista tampoco parece suficiente para deducir apriorísticamente, como hace de nuevo Hinkelammert, que tal postulado derive en una "afirmación dogmática". Un enunciado no científico no es necesariamente dogmático. Por ejemplo, pudiera argüirse que nos enfrentamos a un enunciado "pre-científico", en el sentido de que no pudiendo demostrar empíricamente la aproximación a un estado perfecto de competencia, tuviéramos necesariamente que inferir de tal hecho, la ausencia de realidad (no dogmática) del enunciado.

Lo lógico sería examinar el grado de veracidad de aquellas condiciones del mercado "empírico" que permiten al pensamiento neoclásico advertir la posibilidad de un estado de perfecta competencia. Solo para el caso en que las condiciones que conjugan tal aproximación se revelaran empíricamente implausibles, sería legítimo juzgar el pensamiento neoclásico como estrictamente dogmático. ¿Qué es, por ende, aquello que procura al mercado empírico presentarse como enlace necesario hacia la competencia perfecta? De acuerdo con Hayek solo a través de un mecanismo de precios libres derivado de una incorruptible libertad de contratación y de la consiguiente garantía que supone la propiedad privada, "la tendencia al equilibrio llega a ser más que un ejercicio de lógica pura y se transforma en ciencia empírica" (1952:28). Por consiguiente, es el conjunto de precios forjados en el mercado como "sistema de conmutación a distancia" en el que cada agente adapta sus decisiones a un sistema de competencia perfecta, lo que tendrá que ser corroborado empíricamente.

Solo si de su análisis podemos inferir -o al menos no negar de forma taxativa- un conocimiento empírico claro y decible derivado de un definitivo aprendizaje hacia la competencia real, el dogmatismo de los economistas de "agua dulce" quedaría hipotecado a futuras averiguaciones. Como veremos en las siguientes líneas ello se encuentra fuera de todo análisis claro y evidente.

En concordancia con el pensamiento neoclásico, los precios funcionan como alternativa a la falta de un conocimiento perfecto por parte de los agentes que intervienen en el mercado: "Fundamentalmente, en un sistema en el que el conocimiento de los hechos relevantes se halla disperso entre varios individuos, los precios pueden actuar como elementos de coordinación de las acciones individuales llevadas a cabo por diferentes sujetos, en el mismo sentido en el que las valoraciones subjetivas ayudan a los individuos a coordinar parte de su plan" (Hayek 1997:222).

Solo por medio del mimético acoplo de las reacciones individuales en el mercado libre e institucionalizado a partir de los precios, la racionalidad limitada de los agentes queda hipotéticamente desplazada de las decisiones irracionales y, por consiguiente, del supuesto de imperfecta competencia. Ahora bien, la cuestión gana relevancia cuando abstraemos la generación de los precios de la realidad empírica y asumimos el realismo que le supone el enfoque neoclásico.

Para los economistas de "agua dulce", el mercado se convierte por medio de los precios libres en el mecanismo capaz de crear información necesaria como para que de forma no intencionada todas las decisiones queden arregladas en un innegociable encuentro hacia la competencia perfecta. ¿Sin embargo, 
son las reacciones recogidas en forma de precios suficiente como para que sin intervención exógena el sistema se encamine espontáneamente hacia el equilibrio general? De nuevo Frank Hinkelammert niega categóricamente tal posibilidad. Para el economista alemán el mercado nunca transmite información. Los precios no serían más que depósito de las innumerables reacciones ex-post generadas entre agentes, pues de otra manera podríamos anticipar sus reacciones: "el mercado suple la falta de conocimiento pero jamás transmite información: no es ninguna calculadora sino simplemente un mecanismo que transmite reacciones" (Hinkelammert 2002:290).

A partir de este razonamiento se llega a la conclusión de que tales indicadores no arrojarían luz sobre qué actividades desarrollar sino que más bien supondría un "ir cerrando caminos". Este hecho desembocaría en una verdadera idolatría del mercado, pues ¿qué es sino aquello que indican los precios? Si ellos no son más que reflejo de reacciones, la incertidumbre asociada a la acción -demanda y oferta- no quedaría anulada. Y por tanto, el agente no se encontraría sometido a una "máquina de registro de cambios", sino que abandonado a la incertidumbre de sus decisiones caería preso en la caoticidad de la realidad.

Empero, más allá de lo acertado que Hinkelammert esté sobre el ejercicio dialéctico que suponen los precios como indicadores de reacción/información versus conocimiento, ello no eliminaría taxativamente la posibilidad de una posible tendencia hacia la perfecta competencia, pues siempre se podría argüir que tales reacciones se encuentran motivadas desde el ejercicio inconsciente que generan las dinámicas evolucionistas. Nada niega a priori que las distintas reacciones ex-post pudieran conducir las decisiones de cada uno de los agentes hacia el equilibrio general, aunque ello ya podría ser condición de suficiencia para negar cualquier supuesto de elección racional resultante. El sentido de la negación acerca de la aproximación empírica a la competencia perfecta pasaría por examinar entonces la plausibilidad de aquellos principios que constituyen la generación de los precios. Solo desde la imposibilidad fáctica de tales supuestos podríamos admitir que los precios fueran incompatibles con el objeto de acercar las decisiones individuales a un estado de competencia perfecta.

El supuesto de los precios como indicadores de información reposa sobre dos principios determinantes: el primero es de carácter institucional -propiedad privada y libertad de contrato-y responde directamente a la génesis de lo que son los precios libres. Por otro lado, se da una presuposición antropológica que permite el obrar racionalmente a partir de las reacciones generadas desde esos mismos precios. Es este segundo principio el que conduce hacia aquellas "reacciones adecuadas" que sometidas a los precios libres nos encaminarían hacia la competencia perfecta. Tal y como sostiene Zanotti: "no es más que el análisis experiencial de la naturaleza humana, al estilo de Hume, Smith, Ferguson, lo único que nos puede llevar a universalizar una hipótesis general de tendencia al aprendizaje [...] suficiente a efectos de la coordinación" (2012:88). Empero, ¿que atestigua que tal hecho sea seguro, y que por tanto, el agente reaccione racionalmente a tales influencias antropológicas? Aquí de nuevo la realidad se revela problemática. Los economistas de "agua dulce" tienen que suponer frente a lo planteado por Gray (1995) que el individuo actuará como un perfecto homo economicus.

Una aproximación a la competencia perfecta exigiría la posibilidad de un razonamiento limitado pero no arbitrario. Siendo arbitrario se mostraría incompatible con el proceso que supone la innegociable ordenación hacia la competencia. Una razón de naturaleza auto-interesada y motivada por el esquema de Bentham de utilidad conseguiría acercar las dinamitadas decisiones individuales hacia la competencia perfecta. Ahora bien, ¿qué asegura que tal relación antropológica ocurrirá en tales términos? 
De acuerdo con el profesor Gil Calvo (2009) existirían al menos tres razones por las que los individuos no serían sujetos "de" sus intereses sino sujetos "a" sus intereses. A partir de razones empíricas, lógicas y explicativas las preferencias individuales se encontrarían despojadas de cualquier "racionalidad arquimédica", y por ende, liberadas del orden impuesto por el marco neoclásico. La decisión de cualquier agente siempre lleva inserta una meta-elección. No solo elige aquello que prefiere sino que también decide sobre la conveniencia o no de preferir lo preferido. En esta línea Carvallo propone un razonamiento "directivo" permitiendo "a las personas involucrarse con su entorno social para evaluar lo más conveniente [...] no solo elige qué quiere hacer, sino también qué clase de ser humano quiere ser" (2013:44).

Incluso profesores como Gabriel J. Zanotti, admirador y estudioso de la doctrina austriaca, reconoce en un excepcional ejercicio de humildad intelectual las limitaciones intrínsecas que el mecanismo de aproximación del mercado a la competencia perfecta supone cuando afirma lo siguiente: "Creo que lo mejor que podemos decir es que si la alertness empresarial es suficiente, y hay condiciones institucionales de libre mercado, entonces las expectativas tenderán a la coordinación. O sea, una proposición condicional cuyo grado de verdad del antecedente es relativamente incognoscible, o que a lo sumo podemos suponer por una antropología filosófica a la escocesa donde suponemos una naturaleza humana ni sabia ni ignorante absolutamente y que en condiciones normales de mercado libre tiende a aprender. Y no mucho más" (2012:82).

Esta cuestión es tan reveladora y crítica para el mismo pensamiento neoclásico que los economistas de "agua dulce" no ven alternativas a su negación. A riesgo, eso sí, de presentar como único principio de causa una razón teológica al más puro estilo tomista donde la competencia perfecta no fuera más que una visión del orden natural de las cosas. Esta mirada no se encuentra ausente a esa capacidad de aprendizaje del que hace referencia Zanotti sino que la justifica. El aprendizaje nos dice "sobre qué" precios tenemos que derivar nuestras decisiones pero nada dice sobre "el qué" ni "el cómo" de lo aprendido tuviera que resultar en una menor dispersión del conocimiento existente, y consecuentemente en un acercamiento a la competencia perfecta. Para que tal hecho aconteciera efectivamente tendría que suponerse un presupuesto "teológico" por el cual la reordenación del conocimiento disperso implicara necesariamente un acercamiento hacia el estado óptimo. Una especie de Dios sin Dios cuya determinación se encontrara incorporada a cada una de las decisiones tomadas por los agentes. De cualquier otra manera el carácter previsor y anticipatorio que exige el principio de aprendizaje quedaría como sostiene el propio Kirzner en su "teoría de la empresarialidad" en una mera "capacidad intelectual intuitiva, conjetural de presuponer por donde van a circular las valoraciones de los demás participantes una capacidad de interpretación" (1997:69), pero nada más.

\section{Referencia conclusiva}

Con este texto hemos pretendido desentrañar sumariamente los débiles fundamentos que rigen el pensamiento de los economistas de "agua dulce". Estas debilidades pueden resumirse en la empírica imposibilidad de la competencia perfecta y del irrealismo analítico del concepto de aproximación a tal estado de perfección.

Con respecto a la primera de las derivaciones parece evidente que la competencia perfecta no sea más que una incoherencia empírica. Si la competencia es conflicto, el perfecto de los conflictos es la anulación total de cada uno de ellos. La perfección se revela como ausencia de contra-venencias siendo éstas el fundamento necesario para competir. Por otro lado, los fundamentos antropológicos que recogen la formalización de los precios como mecanismos de orientación hacia el equilibrio se revelan de forma 
imperfecta. Razones de tipo lógico, empírico y explicativas limitan un perfil antropológico dado hacia el orden. Un orden que además exige un ánimo muy particular de la voluntad del sujeto de "ser autointeresado", que igualmente excede de la lógica racionalista.

Por todo ello podemos concluir sosteniendo que la defensa a ultranza del liberalismo económico no supera en ningún momento la frontera de lo ideológico, siendo su entonado pragmatismo no más que un recurso con el que disimular el intrínseco carácter teológico que acompaña a su doctrina. Ahora bien, equivocado se encontraría el lector si cree que con ello los economistas de "agua salada" pudieran apuntarse un tanto en mor a sus intereses epistémicos. La fragilidad empírica del pensamiento neoclásico encuentra a nuestro juicio correspondencia directa con aquellas escuelas de pensamiento regidas desde el principio de planificación perfecta. Demostrar este último enunciado será ejercicio que el tiempo atenderá.

\section{Bibliografía}

Albert, H. 1961. El mito de la razón total. Pretensiones dialécticas a la luz de una crítica no dialéctica. Madrid: Taurus.

Carvallo, C. 2013. La moral y los modelos de optimización económica. Revista Cultura Económica 31(85):39-50. http://www.uca.edu.ar/uca/common/grupo83/files/4-_Carvallo_Spalding.pdf

Gil Calvo, E. 2009. Crisis crónica: la construcción social de la gran recesión. Madrid: Alianza Editorial.

Gray, J. 1995. Liberalisms: essays in political philosophy. Oxford: Oxford University Press.

Hayek, F. 1952. The sensory of order: an inquiry into the foundations of theoretical psychology. Chicago: University of Chicago Press.

Hayek, F. 1997. El uso del conocimiento en la sociedad. REIS 80(97): 215-226.

http://www.reis.cis.es/REIS/PDF/REIS_080_12.pdf

Hinkelammert, F. 2002. Crítica de la razón utópica. Bilbao: Desclee de Brouwer.

Kirzner, I. 1997. Entrepreneurial discovery and the competitive market process: an Austrian approach. Journal of Economic Literature 35(1): 60-85.

Krugman, P. 2009. How did economists get it so wrong? The New York Times Magazine September, online version $h t t p: / / n y t i . m s / 1 J a o b j q$

Kurz, H. 2010. ¿Sobre el estado lúgubre de la ciencia lúgubre? Investigación Económica 69(274): 17-41. http://www.scielo.org.mx/scielo.php?script=sci_arttext\&pid=S0185-16672010000400002

Mandel, E. 1986. In defence of socialist planning. New Left Review 159(1): 5-22.

Mirowski, P. 2013. Never let a serious crisis go to waste: how neoliberalism survived the financial meltdown. Edinburgh: Hewer Text.

Skidelsky, R. 2009. El regreso de Keynes. Madrid: Crítica. 
Stiglitz, J. 2012. El precio de la desigualdad. El 1\% de la población tiene lo que el 99\% necesita. Madrid: Taurus.

Wolf, M. 2015. La gran crisis: cambios y consecuencias. Barcelona: Deusto.

Zanotti, G. 2011. Conocimiento versus información. Algunas ideas dispersas para una epistemología de la escuela austriaca de economía. Madrid: Unión Editorial.

Zanotti, G. 2012. Antropología filosófica cristiana y economía de mercado. Madrid: Unión Editorial.

Von Mises, L. 2010. La acción humana: tratado de economía. Madrid: Unión Editorial.

Recibido el 4 ene 2016

Aceptado el 1 mar 2016 